\title{
Vulnerability, Resistance, and Reciprocity: Recasting Responsibilities of Care in Schooling Through Troubling Animal-Child-Adult Encounters Within a School for Marginalized Children
}

\author{
Maria Ejlertsen
}

\begin{abstract}
Maria Ejlertsen is a doctoral researcher at the School of Education, The University of Queensland, Australia. She has lived, studied, and worked in Denmark, Kenya, and Australia. Her interests include (more-than) inclusive education, alternative approaches to education, more-than-human relational perspectives, and multisensory and participatory research methods. Currently, her research focuses on enactments of marginalized children's belongings and identities in a special assistance school, using visual methods and attention to affective material-discursive entanglements. She is a qualified teacher with experience working with marginalized students in primary and secondary schools. Additionally, she holds an MSc in animal husbandry and welfare and has worked as a project facilitator in international development. Email: m.ejlertsen@uq.edu.au
\end{abstract}

This paper troubles enactments of care in schooling and open possibilities of caring otherwise through engaging with a more-than-humanist relational lens of animalchild-adult relationships within a school for marginalized children. I explore two encounters with an animal, child, and myself that challenge my self-perceptions as a caring educational researcher and educator and, within that, what counts as care. By attending to my affective responses within these encounters, I explore how thinking with the concepts of resistance, vulnerability, and intra-action can offer generative possibilities of care in schooling. Through this, possibilities of care grounded in ontological reciprocity and openness emerge to enable a reimagining of how we might care differently with children and animals.

Key words: care; animal-assisted interventions; alternative schooling; intra-action; affective response-ability; morethan-human(ist)
The notion of care is central to our ideas and expectations about schooling. As argued by Mills, Keddie, Renshaw, and Monk (2017, p. 70) the vast majority of schools are concerned with constructing their school as a "caring place." However, what it means to care in schools is often taken for granted as binary human relationships of a "carer" and a "cared-for," with the teacher firmly placed as the active carer of passive, caredfor students (Mills et al., 2017; Noddings, 2012). Furthermore, such caring relations are often seen as "natural" and positive adult-child relations and are seldom interrogated in detail (Ailwood, 2017). Yet, discourses of care are also used to support exclusionary practices in schools, where children with "disruptive" nonconforming behaviours are pushed out of mainstream schooling on the grounds of caring for both them and the other, compliant, children (Graham et al., 2015; Mills et al., 2017; Thomson \& Pennacchia, 2016; Tuck, 2011).

At the same time, enactments of care focusing on therapeutic approaches in working with marginalized students are becoming increasingly common in both alternative schools and mainstream schools, parallel to discourses of care as segregation and exclusion (Mills \& McGregor, 2016; Mills et al., 2017; Thomson \& Pennacchia 2016). Other-than-human animals are increasingly being incorporated into schooling approaches in support of children's learning and well-being in such therapeutic approaches (Brelsford et al., 2017; Jalongo, 2015; Serpell et al., 2017). Such approaches tend to employ a humanist and developmental perspective that portrays animals as instrumental to supporting the normative development of the child (Hohti \& Tammi, 2019). This support can either be given through providing a caring role for the child's well-being or learning, or through teaching the child caring skills, such as responsibility, empathy, and self-regulation (e.g., Jalongo, 2015; Serpell et 
al., 2017). Additionally, perspectives of animals as nonjudgmental, innocent, and unable to "speak back" tend to dominate (Tipper, 2011). However, while children frequently draw attention to the importance of animals when asked about what matters to them in their lives, these relations are rarely explored in depth (Tipper, 2011).

Furthermore, as Thomson and Pennacchia (2016) warn, therapeutic and animal-assisted approaches to care in schools often retain a core function as "disciplinary regimes of care" that ultimately aim for behavioural compliance and normativity within the frames set by schooling. For children who are marginalized in schools, such a lens of caring animal-child relations invites a deficit perspective of them as flawed and in need of being fixed in order to "fit in." For the animals, it reduces them to passive instruments. Yet, it is noteworthy that, while educator-child care relations tend to maintain presupposed, fixed carer and cared-for roles, the caring roles in animal-child relations are often less clearly defined and more dynamic. Hence, animal-child relations provide promising avenues for exploring possibilities of care beyond normative notions of adult-child care relations in schools.

The role of animal-child relations in reworking how we view and do education is increasingly being explored in educational research (e.g., Hohti \& Tammi, 2019; Somerville, 2018; Taylor \& Pacini-Ketchabaw, 2015; Tooth \& Renshaw, 2018). This paper contributes to such work by exploring what a focus on animal-child-adult encounters through a more-than-human(ist) relational lens can offer to understanding enactments of care in relation to marginalization of noncompliant children in schools. In doing so, the paper responds to Thom van Dooren's (2014) call to hold ourselves accountable to our enactments of care by asking, "What counts as care and why? How else might care be imagined and practiced? In short, what am I really caring for, why, and at what cost to whom" (p. 293, italics in original)? How might placing care at the centre of our work "remake ourselves, our practices and our world" (van Dooren, p. 294)? And, following Haro Woods et al. (2018, p. 46), "how might we mobilize care to "do otherwise" ... [and] what might be required of us ... to open up space for such possibilities to emerge?"

\section{Making sense of animal-child-school encounters}

This study is grounded in a relational "ethico-onto-epistemology" (Barad, 2012a) that is attentive to the "more-than human(-ist)" relationships we, as beings on Earth, are part of. This perspective does not see any beings (animate or inanimate) as fixed, separate, and independent beings. Rather, we are continuously expressed and defined through our relationships with the human and other-than-human world that we are part of and responsible to. This also implies that there are no fixed truths to be known about the world from a detached perspective. Instead, we can only ever know through being in relation with others. Knowing is therefore not primarily a function of the rational mind. Instead, knowing is a doing that is continuously emergent and embodied through our more-than human relationships. As such, being, knowing, and responding ethically to another are not seen as separable from each other. Such ways of making sense of the world have long been articulated from various Indigenous perspectives (e.g., Deloria 1979; Kimmerer, 2013; Kuokkanen, 2007; Lloyd et al., 2012) and have been taken up by other perspectives, such as eco-phenomenology (e.g., Abram, 1997) and the posthumanism and new materialisms (e.g., Barad, 2007; Braidotti, 2013; Haraway, 2008). The term more-than-humanist builds on more than human, coined by David Abram (1997). I use more-than-human(ist) to (1) emphasize the importance of considering other-than-human beings rather than solely focusing on the human and (2) to move beyond a rationalist, Cartesian perspective of the human in the world. I chose such a perspective because it resonates with how I have always already experienced the world I am of and because it allows me to make sense of and articulate important aspects of the research. I do not aim to "decenter" the human, "move beyond the human," or pretend to be able to speak for other-than-human beings. In this paper, I primarily draw on Karen Barad's concepts of posthumanist performativity and intra-action to set out the specific conceptual frames for analysis within the above-described relational lens. I do so because of the distinctive possibilities for analysis the concept of intra-action offers, as will be apparent in later sections. 


\section{More-than-human(ist) performative intra-action}

There need not be "a doer behind the deed," the "doer" is variably constructed in and through the deed. (Butler, 1990, p. 181)

Existence is not an individual affair. Individuals do not precede their interactions; rather, individuals emerge through and as part of their entangled intra-relating. (Barad, 2007, p. ix)

Barad draws on Judith Butler's notion of performativity, which troubles the humanistic perspective that subjects exist prior to their interactions with the world around them and accounts for the processes through which subjects are constituted as intelligible (Butler, 1990). As the above quotes illustrate, performativity sees individual subjects as being given meaning (i.e., coming into being) through continuous iterative enactments. While Butler tends to focus on how human beings are given meaning and come to matter, Barad insists more explicitly on exploring the ways both human and other-than-human beings come to matter in relation to each other (Niesche \& Gowlett, 2019). Furthermore, while Butler arguably maintains interactions between separate human subjects and nonhuman objects as the centre of analysis, Barad not only questions the distinction between subjects and objects but also explores how the very boundaries between any subject/object are enacted and how this comes to matter. To this end, her idea of intra-action is central.

Intra-action, as opposed to interaction, makes explicit the ontological inseparability of subjects/objects prior to the iterative acts that define their boundaries. It emphasizes that the boundaries that separate beings are continuously cut and recut through our performative intra-actions within the entangled relations we are of. As such, individual beings (animate and inanimate) never exist in singular but are always plural as individuals emerge through their relations to each other. The subject/object boundaries that sediment depend on which (intra)actions are given attention and made to matter. Hence, questions of individual agency are decentered and responsibility for the different cuts that are enacted and how they come to matter is put centre stage. Here, the term "being" simultaneously signifies a materially embodied form and an active performative verb of be-ing in the world (Butler, 1991), a beingin-doing and doing-in-being continuously shaped through our relational intra-actions. I use the term being rather than becoming to counteract the future-oriented focus on the child becoming a rational autonomous adult that is common in developmental childhood studies, as well as to maintain a focus on the responsibilities to that which is already being enacted and enabled rather than the not-quite-here-yet of becoming.

\section{Affective response-ability as an embodied, emergent approach to research}

The research approach for this study emerged during the research as I sought to make sense of my own and others' responses within the research process. Based on my experiences in participatory agricultural development and as a teacher and teacher aide working with marginalized children, it was important to me to reject the role of an authoritative, expert researcher. Therefore, I did not set out to employ a set of clearly outlined and predefined methodologies and methods. I aimed to be open to how those (not) participating in the research shaped the process and to relinquish some control over what the research should look like. I conceptualize the emergent research approach as "affective response-ability."

Several scholars engage with the term response-ability within a more-than-human relational lens, including Kuokkanen (2007), Haraway (2008), and Barad (2012a, 2012b). In alignment with the conceptual framework presented above, I mainly draw on Barad's writings here to articulate the perspective of response-ability engaged with in this study. Barad suggests that being response-able requires an openness to be in relationship with an "other" that allows for the other to respond otherwise, as well as being responsive to their responses by accounting for the cuts that are intra-actively made (Barad, 2007). Such a response-ability cannot be intentionally calculated as 
this would limit what can be imagined by a response-able "I" (Barad, 2007, 2012a). Being response-able holds me accountable for my own intra-active entanglements within the research and the responsibilities this entails in how certain ontological and individualizing "cuts" come to matter over others in the research encounters. It requires being attentive to the affective responses I experience in the research encounters and "staying with the trouble" they pose (Haraway, 2016).

Affect is here conceptualized as a material embodied form of knowing-in-being that is felt as physiological sensations of (dis)comfort in my intra-actions with the world I am of, without necessarily belonging to me alone. This perspective differs from notions of affect that draw on Brian Massumi's work to conceptualize affect as the ability to affect and be affected, and a nonconscious, pre-personal intensity that moves between bodies (Massumi, 2004). Rather, as an approach to research, affect is what alerts me to the continuous process of boundary making and remaking taking place through my performative intra-actions with the more-than-human world within specific encounters. It is not the process of boundary making itself but rather the knowing-in-being of the process. This knowing-in-being is often beyond cognitive articulation and reasoning but not beyond consciousness. It is what makes me drive my spouse crazy by trying out numerous different seats at a café before being at ease, and the visceral sense of dis-ease when attempting to fulfill "perfectly reasonable" expectations of social engagement that nevertheless leave me feeling compromised. And it is what forces me to return to certain encounters in this research again and again.

\section{Ubuntu School and Helping Hearts Animal Rescue Centre}

Ubuntu School is an independent school located in South East Queensland, Australia, catering to approximately 115 boys aged 8-15 years. Most of the children at the school have been pushed out of mainstream schooling through multiple suspensions and exclusions due to disruptive, nonconforming behaviours. The starting point for the research project with Ubuntu School which this paper draws on was student belonging in school. Working with marginalized students in mainstream schools, I had experienced the complex processes of students, and myself, oscillating between various levels of engagement, resistance, and resignation with the prevailing frames of schooling. I was interested in exploring these processes of becoming a subject of schooling in a manner that would embrace complexity and nonlinearity, as well as allow a focus on what matters to the students themselves. Belonging as a dynamic and relational concept invites exploration of affective, spatial, nonhuman, and material aspects in shaping processes of subject formation (Cuervo \& Wyn, 2014; Wood \& Waite, 2011; Wright, 2015; Yuval-Davis, 2006). As such, a focus on student belonging in school served as a rich conceptual and methodological entry point.

I visited Ubuntu School approximately twice a week over a four-month period in 2018. During my first visit, staff and children were informed about the research project and their potential participation in detail, and they had invited me into their classrooms. Throughout the visits, I participated in whole-school events, classroom activities, and excursions with the children and staff. During my visits, I would take part in group activities, assist the classroom staff with activities, and support children as requested. I recorded conversations with eight children and 13 school staff about what matters to the children's sense of belonging in school. Conversations with participating children centred around photos taken by each child of places and things that "matter to how they feel about school and their sense of belonging at school." Each child was given a tablet and asked to take any photos they wanted while at school or on excursions. Based on consultations with school staff, I walked with each child as they took their photos to provide support and supervision. The conversations and encounters referred to in this paper involved children aged 9-12 years, as well as staff. All names used in reference to places, animals, and humans are pseudonyms. 


\section{Animal-child relations at Ubuntu School}

The school offers a broad range of co-curricular activities, including a weekly visit to Helping Hearts, a small, local animal rescue centre. Helping Hearts is the home of "Joyce," who runs the centre on a semi-suburban acreage. The number of animals living with Joyce varies; however, the "regulars" include four dogs, one horse, two ponies and several cats, chickens, ducks, and guinea pigs. The visits to Helping Hearts are largely unstructured. The children follow a loose routine of first going to the paddock. Here they are free to roam around and interact with the animals there, typically the horse, ponies, dogs, goats, and sheep. Next, they go to Joyce's house, where they collect eggs, interact with the smaller animals on her veranda, and have a drink and a snack. Each class at the school also has one or more "class pets" which are regularly brought to school by the teacher they live with.

When asked to take photos of things that matter to how they feel about schooling and their sense of belonging in school, the children participating in the research repeatedly photographed and later talked about animals, including the class dogs and the animals at the rescue centre.

[Of all the photos, which matters most to you?] Oh, well, obviously, it's the dog ... because the dog is cute. (“Reuben," student)

When asked why, several children referred to being calm in the animals' presence but were somewhat tentative in articulating why being with the animals made them feel calm:

[How does “Daisy” (class dog), her being there, make a difference to you?] ... I don't know. (Reuben)

Because ... animals can calm down people ... like since Daisy has been here, l've felt a lot more calmer. [So what do you think it is about Daisy being here that makes you feel calmer?] Well, I don't know ... it's like ... when we feel angry, they let her off the lead, because she is on a lead. And Daisy comes to me, or other boys. Yeah, and it's good. (“Austin," student)

[Being with animals] keeps people calm, it's a reward for people being good ... it's just calming, they understand you and everything. They understand you in ways humans can't. (“Ben,” student)

When school staff were asked about why the animals at school seemed to matter to the children, similar sentiments of keeping them calm were expressed:

"Bear" [class dog] was here the other day and they all loved having some kind of [interaction with him]. And that's their kind of coping mechanism to calm themselves down too. ("Mike," youth worker)

I think it's just like, they [the animals] are just so peaceful and you just get such a calm feeling when you're feeling crappy. Like for me personally, I know she's my dog, but in the afternoons if we've had a really bad day and she's been in there [staffroom next door], if I open the door and let her in here, it's almost like everything's better. Like you lose that anger and that feeling of just not ... feeling crap. I don't know, it's just like an automatic release of that. ("Hannah," teacher)

Here, children and staff alike reinforce perspectives of the children at the school being angry individuals whose belonging in school rests on managing their anger and remaining calm. The animals are instrumental in supporting this agenda. This can be seen as reproducing dominant enactments of care in mainstream schools that focus on teachers ensuring behavioural compliance (Mills et al., 2017; Thomson \& Pennacchia, 2016). However, the above quotes also illustrate the sense that there is more to these animal-child-school relationships that cannot easily be articulated-something which is also noticed by a teacher in Hohti and Tammi's (2019) research with animals and school-age children. 
The two encounters that are the focus of the remainder of the paper are from one of the weekly excursions to Helping Hearts. In both encounters, a child is on their own with an animal and in different ways is disrupted by me. I use these unintended disruptions as entry points for exploring the notions of care these encounters disrupt and to suggest how attention to the entangled animal/child/researcher/school relations might allow for other, potentially more subversive, responsibilities of care to emerge.

\section{Care through resistance, vulnerability, and reciprocity in an animal-child-researcher encounter}

Cookie is grazing as I walk across the paddock toward him and Kevin, skipping over the small stream winding through the grass. Kevin took Cookie for a walk in the paddock but now seems anxious to take the pony back to the shelter up the hill. He stands in front of Cookie holding the lead rope attached to the halter, calling for him to follow. The other staff and children are leaving the paddock, and I move toward Kevin and Cookie to offer my help. As I get closer, Kevin does not appear to want my help. Torn between not wanting to impose and not wanting to leave Kevin on his own, I discreetly walk up behind the pony, hoping this will make him move along. Cookie continues to graze without looking up, while Kevin appears to get increasingly frustrated watching the others leave. It is his first visit to this place, and I imagine that he does not want to be left behind. I give Cookie a gentle but firm push on the hindquarters to get him moving. The reaction from Kevin is instant and strong: "You can't do that!" I tell Kevin that it won't hurt him. "It will just let him know what you want." "You can't make him do that" Kevin responds, upset. Cookie continues to graze, and I offer to stay with Cookie so that Kevin can catch up with the others. Rather than answering, he attempts to take off Cookie's halter. He struggles with opening the buckle and I again offer to help. He reluctantly accepts my help after further unsuccessful attempts. The halter strap is old and frayed, and as I lift the buckle to wedge the strap out, Kevin yells, "Stop! You're hurting him!" The next moment, the halter comes off and falls to the ground, leaving Cookie to continue his grazing without once lifting his head. Kevin runs after the other children and staff and I follow behind with halter and lead rope in hand.

This encounter could be brushed off as an insignificant event in an otherwise intense school setting, where my wellmeaning offer to help was unwanted yet necessary to ensure Kevin was not left behind on his own with Cookie. It could be seen as Kevin overreacting and shouting at an adult without valid reason and thus being in need of reprimand, as would be the case in many mainstream schools. However, the encounter stays with me and will not let go. Tuck and Yang (2011) speak of youth resistance as "identify[ing] and exploit[ing] hair-line fractures and fault lines within systems" (p. 525). Here, Kevin's and Cookie's resistance within the encounter offer an opportunity to interrogate the fractures and fault lines of paternalistic and therapeutic perspectives of care in animal-child relationships and schooling. Through a lens of more-than-human performative intra-action, I draw on Butler's $(2016,2020)$ writing on vulnerability and resistance and Kuokkanen's (2007, 2010) writing on reciprocity and learning to further consider how this might enable us to imagine caring relations in schools differently.

Butler (2020) troubles the justice in characterizing specific groups or individual beings as vulnerable and in need of care, if "by care we mean an ongoing and unconflicted ... disposition of paternalistic care" (p. 3). Rather, she encourages an exploration of how vulnerability and resistance work together to variously enable and disable opportunities for care. She uses the phrase "resistance to vulnerability" to show how dominant authorities' responses to resistance, such as public demonstrations, often are harsher than seemingly necessary because the resistance by "vulnerable" groups exposes their own vulnerability. Hence, she highlights how, through groups or individuals being designated as "vulnerable," powerful resistance can also emerge, that is, resistance through vulnerability. Therefore, attending to the multilayered resistances in an encounter and the vulnerabilities that emerge in acts of resistance may create possibilities for being otherwise. 
Both children and companion animals are often seen as inherently vulnerable and in need of care (Gorur, 2015; Hohti \& Tammi, 2019). From a lens of performativity, this is a precarious positioning that requires continued reenactment in order to be upheld; both Kevin and Cookie challenge this positioning. In schools, the perceived resistance by some children who are unable or unwilling to comply with expected behaviours negates their claim to vulnerability and care in favour of the school's (i.e., principal's, staff's, and other parents') resistance to vulnerability. Instead, the children are positioned as risky and "at risk" (te Riele, 2006) to themselves, others, and the system of schooling itself. Similarly, a companion animal's claim to care rests on conforming to our human lives and expectations of what makes an agreeable companion. Stepping outside of the parameters of innocence and vulnerability, regardless of the underlying issues, can quickly lead to sympathy being withheld, as anyone living with an anxious, reactive dog will know. Many of the animals coming to Helping Hearts are, like the children, there because they were unable or unwilling to conform to expectations and/or became too burdensome to care for.

Being response-able to the discomforts I experienced through Kevin's and Cookie's resistance to my help forces me to stay with the vulnerability it exposes in my perception of myself as a caring researcher, educator, and animal lover. When my (to me) discreet attempts to help Kevin were resisted by Cookie's indifference and Kevin's strong reaction, my position as a knowledgeable and caring researcher / educator / horse owner helping Kevin to "care" for Cookie was challenged. Our roles shifted: I, the knowledgeable researcher/educator caring for the vulnerable student in need of help with the aid of the instrumental and willing pony became a perpetrator, while Kevin became the carer and Cookie the vulnerable cared-for. However, Cookie, by being seemingly indifferent to the unfolding drama, powerfully unsettled any such simplified notions of care by disrupting both our claims (mine and Kevin's) to the role of carer. Rather than teaching Kevin about horses and positioning him as a nonreactive horse carer through my caring, I was taught about what it might mean to care by both Kevin and Cookie. My involvement shifted, from needing to intervene and manage both Kevin's and Cookie's resistance, to acknowledging and allowing possibilities for response that change the caring relation. Thus, exploring the complexities of multiple threads of caring taking place in the animal-child-researcher encounter (Hohti \& Tammi, 2019) offers every-body involved alternate ontological possibilities.

Embracing rather than resisting vulnerability and the discomforts that may follow enables possibilities of care as ontological reciprocity. It suggests a possibility of care where "the sense of exposure to the other is crucial" (Barad, 2012b, p 217). It is an ontological reciprocity that accepts uncertainty and letting go of control and is open to everyone involved being affected through the caring relation. Like the circular reciprocity of the gift offered by Kuokkanen (2007), such reciprocity does not rest on symmetrical relations of giving and taking between individuals. It cannot be reduced to moral obligations or zero-sum transactions. Rather, such reciprocity emphasizes the primacy of relationships over individuals and embraces the mutually beneficial opportunities for learning and being differently. Here Kuokkanen (2010) importantly distinguishes between a learning which seeks to "know the other" and a learning in order to receive. Rather than assuming the entitlement (or even possibility) to know the other, or to know what is best for the other, a reciprocity grounded in a willingness to learn to receive allows for sedimented boundaries of "oneself" to be loosened and reworked in ways that extend this opportunity to the others in the encounter without imposing whether and how the opportunity is taken up. I cannot speak on behalf of Kevin and Cookie. Nevertheless, by being open to be affected and undone by the multiple possibilities of caring in the encounter, I experience the encounter in a new light, which offers everyone involved greater ontological possibilities to respond and be otherwise, not least myself. In the next section, I build on this idea by exploring how a child/cat/living-room/researcher encounter might further add to such possibilities for caring otherwise in schools. 


\section{Care as infinite alterity in an animal-child-living-room encounter}

While sitting on the veranda with children holding ducklings and guinea pigs, I notice that Ben has moved into the adjacent living room. He is crouching on the floor across from a scrawny black and white cat with only a small stump for a tail. He is patiently holding out his hand, waiting for the cat to touch it. After initial hesitation, the cat moves forward until his nose touches the hand. Then his whole face and body touch and rub against Ben's arm and legs. I came along to the animal rescue centre because Ben asked me to be here. He wanted to take photos of the animals and needed me to bring the school's tablet. I move toward the living room, but before I get to the doorway, Ben stands up and leaves. I stay on the veranda talking to some of the other boys and Ben walks back in to sit with Tux. A few minutes later, I walk back to the living room entrance and quietly tell Ben that the tablet is available if he wants to take any photos. He answers "no" under his breath and walks away from Tux and the living room again. I feel like I have unwittingly intruded on something important. Fifteen minutes later we leave the animal rescue centre without having taken any photos.

Again, the encounter stays with me and will not let go. I am left with the struggle to make sense of and articulate what unfolded and how the camera's and my presence altered this. Here I have found Barad's concepts of intra-action and the inhuman indispensable. Barad (2012b) employs the concept "inhuman" to signify the "indeterminate non/ being non-becoming of mattering and not mattering ... the liminality of no/thingness" (p. 216) and the "infinite alterity" (p. 218) which is possible within our intra-acting. In other words, an infinity of constitutive possibilities for ontological boundary setting, and thus possibilities of being, exists within each and every encounter but is often not acknowledged and thus the encounter is limited to finite, expected ways of being. To me, this indeterminacy and infinite alterity of the inhuman is what comes closest to describing my experience of the intra-active encounter with Ben and Tux.

Rather than merely reframing the boundaries of who Ben can be (e.g., a child who is good with cats) or identifying with the story of the cat, a suspension of individual subject boundaries of Ben and Tux within the encounter is made visceral. In their entangled encounter, Ben ceases to be a boy needing to be calm and manageable to fulfill the role of a viable student and Tux similarly ceases to be an angry, shy rescue cat. Instead, I argue, the encounter allows for momentarily letting go of notions of "self" and "other." This letting go provides a freedom for both from needing to be or do anything and thus allow a momentary reimagining of what it means to be a "good" student and companion animal. It takes the notion of reciprocity in caring relations even further by suggesting a caring relation beyond a giver and receiver altogether. There is no designated carer or cared for, yet the encounter is caring and rewarding for both involved, as is hinted in later conversations with the woman who runs Helping Hearts Animal Rescue Centre:

I got a new cat here that was really angry and one little voice said: "Can I go in and see Tux? Because Tux really likes me." So, each week [Ben] wanted to go in and see Tux and Tux actually started to trust people. So, his company has actually helped the cat as well. (Joyce)

My presence with the camera interrupted and altered the caring relation between Ben and Tux and I therefore reduced rather than expanded the ontological possibilities of everyone involved in the encounter. This action resedimented them as a student and a cat separate from each other, forcing questions of who is what to whomboy taming cat? cat taming boy? - questions that unwittingly interrupt caring relations of shared vulnerabilities within the cat-boy intra-action and invite a (re-)instatement of (self-) care as resistance to vulnerability, which Ben enacts by leaving. 


\section{Responsibilities of caring differently for more(-than) inclusive schooling: Care as ontological reciprocity and indeterminacy}

How would we feel if it is by way of the inhuman that we come to feel, to care, to respond? (Barad, 2012a, p. 81)

Exploring care in animal-child-school relations through a lens of intra-action, vulnerabilities-in-resistance, and the inhuman has allowed for a dynamic and complex perspective of what counts as care in animal-child relations and schools to emerge. As evident in my encounter with Kevin and Cookie, this is not to romanticize animal-child relations or resistance. The role of the animal-child relationship in schooling lies not in their innocent and mutual ability to care for each other, although this possibility may be present and rewarding at times. It does not rest on animals being inherently nonjudgmental, nor passive and unable to "speak" back. Rather, it offers us, as adult human beings involved in education with children, an opportunity to question how our animal-child-adult-school relations can teach us to do schooling differently. Might it be possible, as Hohti and Tammi (2019, p. 11) suggest, "that animals as teachers intervene and ask us to listen differently"?

While I cannot speak for the children and animals in this study, I have pointed to how being response-able to animal-child-adult relations in schools expanded the possibilities of being educator/student/animal and allowed me to be educator/researcher/animal-lover differently. It is my hope that this approach might open possibilities to think and do schooling and animal-child relations differently in ways that will make a positive difference to all involved. Rather than seeing children's noncompliance as defiance or lack of self-regulation (or even theirs alone), perhaps we might see it as a shared expression of "a deep yearning for something better" (Nolan, 2011, p. 570) and an invitation to everyone involved to open up the possibilities of caring differently in schools. You, as the reader, may gain your own insights from these encounters based on the particular entangled relations you are part of. What I have gained, as I return to and am rewoven by the encounters, is an urgency to be present to and responsible for the possibilities of being, knowing, and caring that our everyday acts of care create for everybody-every day. For me, this includes considering how the more-than-human relationships we engage in, within and outside of the classroom, contribute to or detract from the ontological opportunities offered in our caring relations. It also importantly involves recognizing that being in care-full relation as an educator is not just something I do, but something that does me, and is done with (Haro Woods et al., 2018) rather than for or by the more-than-human relations I am of.

I suggest that such relations of care with animals and children alike require loosening resistance to vulnerability and being open to vulnerability through resisting normative notions of what it means to care and be cared for in schools. However, the aim of this paper is not to advocate for uncritically bringing (more) animals into schools. Rather, it is to pause to consider how our relations with animals—domesticated and wild, large and small—may offer us opportunities to learn and explore what might be possible in schooling and beyond if we pay attention and are willing to be challenged and changed in our "caring" encounters with children and animals alike. Such an openness cannot solely be rationalized, but rather requires attention to our affective responses within continuous processes of ontological intra-acting and boundary setting. As Barad (2007) notes, "the ethical subject is not the disembodied rational subject of traditional ethics but rather an embodied sensibility" (p. 391, italics added). It is through being open to suspend sedimented ontological boundaries and "risk[ing] a shared sense of vulnerability" (Barad, 2017, p. 81) that caring relations emerge. "Jean," a youth worker at Ubuntu School, alludes to this when sharing "what it takes" to work at the school:

You've got to face yourself ... you've got to be prepared that you may have to grow, you know. That you may be challenged in ways that you didn't imagine was gonna be part of your experience. But 
ultimately, that's awesome. Because to me you grow and become more of who you already are.

Research within alternative schooling consistently emphasizes the importance of adult-child relationships when working with students who are being marginalized in their schooling (Mills \& McGregor, 2016; Shay et al., 2016; Thomson, 2014). This paper contributes to understanding how these relationships may come to matter in schools. It offers an opportunity for those working with children in schools to consider the ontological opportunities that are enabled and made to matter in every intra-action. It suggests a perspective of care as emerging through being in reciprocal relation beyond a designated carer and cared-for. This perspective requires recasting rigid notions of adult-child relations in schooling and enabling respectful reciprocal relationships where every being can learn from each other and has something to give and receive in any encounter. Hence, the concepts of vulnerability and care are untangled from being political and paternalistic tools for making abstract claims of sympathy, labelling individuals and groups, and quantifying variables for "fixing" individuals and systems (Gorur, 2015). Rather, vulnerability and care are reworked to insist on everyone being accountable to the ontological work of the caring relations and responses to vulnerability we are always already enacting. This requires acknowledging the ontological reciprocities and multiplicities of care possibilities in these encounters and suspending simplistic notions of who and what beings can be. Rather than attempting to control and manage the "self" and "others," it invites the question of how we can enable and acknowledge windows of infinite alterity in schooling encounters to allow us all to be otherwise. 


\section{References}

Abram, D. (1997). The spell of the sensuous: Perception and language in a more-than-human world. Vintage Books.

Ailwood, J. (2017). Exploring the care in early childhood education and care. Global Studies of Childhood, 7(4), 305-310. https://doi. org/10.11772043610617747977

Barad, K. (2007). Meeting the universe halfway: Quantum physics and the entanglement of matter and meaning. Duke University Press.

Barad, K. (2012a). Intra-actions. Mousse, 34, 76-81.

Barad, K. (2012b). On touching-The inhuman that therefore I am. A Journal of Feminist Cultural Studies, 23(5), 206-223. https://doi. org/10.1215/10407391-1892943

Barad, K. (2017). Troubling time/s and ecologies of nothingness: Re-turning, re-membering, and facing the incalculable. New Formations, 92, 56-86. https://doi.org/10.3898/NEWF:92.05.2017

Braidotti, R. (2013). The posthuman. Polity Press.

Brelsford, V. L., Meints, K., Gee, N. R., \& Pfeffer, K. (2017). Animal-assisted interventions in the classroom-A systematic review. International Journal of Environmental Research and Public Health, 14(7), 1-33. https://doi.org/10.3390/ijerph14070669

Butler, J. (1990). Gender trouble: Feminism and the subversion of identity. Routledge.

Butler, J. (1991). Imitation and gender insubordination. In D. Fuss (Ed.), Inside/out: Lesbian theories, gay theories (pp. 13-31). Routledge.

Butler, J. (2016). Rethinking resistance and vulnerability. In J. Butler, Z. Gambetti, \& L. Sabsay (Eds.), Vulnerability in resistance (pp. 12-27). Cornell University Press.

Butler, J. (2020). Judith Butler on rethinking vulnerability, violence, resistance [blog post]. Verso, March 6. https://www.versobooks.com/ blogs/4583-judith-butler-on-rethinking-vulnerability-violence-resistance

Cuervo, H., \& Wyn, J. (2014). Reflections on the use of spatial and relational metaphors in youth studies. Journal of Youth Studies, 17(7), 901-915. https://doi.org/10.1080/13676261.2013.878796

Deloria, V., Jr. (1979). The metaphysics of modern existence. Harper \& Row.

Gorur, R. (2015). Vulnerability: Construct, complexity, and consequences. In K. te Riele \& R. Gorur (Eds.), Interrogating conceptions of "vulnerable youth" in theory, policy and practice (pp. 3-15). Sense.

Graham, L. J., Van Bergen, P., \& Sweller, N. (2015). Caught between a rock and a hard place: Disruptive boys' views on mainstream and special schools in New South Wales, Australia. Critical Studies in Education, 57(1), 1-20. https://doi.org/10.1080/17508487.20 $\underline{16.1108209}$

Haraway, D. J. (2008). When species meet. University of Minnesota Press.

Haraway, D. J. (2016). Staying with the trouble: Making kin in the Chthulucene. Duke University Press.

Haro Woods, Nelson, N., Danis, I., Elliott, D., Wilson, J., Payjack, J., \& Pickup, A. (2018). With(in) the forest: (Re)conceptualizing pedagogies of care. Journal of Childhood Studies, 43(1), 44-59. https://doi.org/10.18357/jcs.v43i1.18264

Hohti, R., \& Tammi, T. (2019). The greenhouse effect: Multispecies childhood and non-innocent relations of care. Childhood, $0(0)$. https://doi.org/10.11770907568219826263

Jalongo, M. R. (2015). An attachment perspective on the child-dog bond: Interdisciplinary and international research findings. Early Childhood Education Journal, 43(5), 395-405. https://psycnet.apa.org/doi/10.1007/s10643-015-0687-4

Kuokkanen, R. (2007). Reshaping the university: Responsibility, Indigenous epistemes, and the logic of the gift. UBC Press.

Kuokkanen, R. (2010). The responsibility of the academy: A call for doing homework. JCT Online, 26(3), 61-74. https://journal.jctonline. 
org/index.php/jct/article/view/262

Kimmerer, R. W. (2013). Braiding sweetgrass. Milkweed Editions.

Lloyd, K., Wright, S., Suchet-Pearson, S., Burarrwanga, L., \& Country, B. (2012). Reframing development through collaboration: Towards a relational ontology of connection in Bawaka, North East Arnhem Land. Third World Quarterly, 33(6), 1075-1094. https://doi. org/10.1080/01436597.2012.681496

Massumi, B (2004). Translator’s foreword: Pleasures of philosophy. In G. Deleuze \& F. Guattari (Authors), A thousand plateaus. Bloomsbury.

Mills, M., Keddie, A., Renshaw, P., \& Monk, S. (2017). The politics of differentiation in schools. Routledge.

Mills, M., \& McGregor, G. (2016). Engaging students in engaging schools: Lessons from Queensland's alternative education sector. Youth Affairs Network Queensland.

Niesche, R., \& Gowlett, C. (2019). Social, critical, and political theories for educational leadership. Springer.

Noddings, N. (2012). The caring relation in teaching. Oxford Review of Education, 38(6), 771-781. https://doi.org/10.1080/03054985.20 $\underline{12.745047}$

Nolan, K. M. (2011). Oppositional behavior in urban schooling: Toward a theory of resistance for new times. International Journal of Qualitative Studies in Education, 24(5), 559-572. https://doi.org/10.1080/09518398.2011.600263

Serpell, J., McCune, S., Gee, N., \& Griffin, J. A. (2017). Current challenges to research on animal-assisted interventions. Applied Developmental Science, 1-11. https://doi.org/10.1080/10888691.2016.1262775

Shay, M., Morgan, A., Lampert, J., \& Heck, D. (2016). Introduction to the special issue on alternative pathways in education for disenfranchised children and young people in the Australian context. International Journal of Child, Youth, and Family Studies, 7(2), 1171-177. https://doi.org/10.18357/ijcyfs72201615716

Somerville, M. (2018). Posthuman theory and practice in early years learning. In A. Cutter-Mackenzie-Knowles, K. Malone, \& E. Barratt Hacking (Eds.), Research handbook on childhoodnature: Assemblages of childhood and nature research. Springer International Handbooks of Education.

Taylor, A., \& Pacini-Ketchabaw, V. (2015). Learning with children, ants, and worms in the Anthropocene: Towards a common world pedagogy of multispecies vulnerability. Pedagogy, Culture, \& Society, 23(4), 507-529. https://doi.org/10.1080/14681366.2015.1 $\underline{039050}$

te Riele, K. T. (2006). Youth "at risk": Further marginalizing the marginalized? Journal of Education Policy, 21(2), 129-145. https://doi. org/10.1080/02680930500499968

Thomson, P. (2014). What's the alternative? Effective support for young people disengaging from the mainstream. Princes Trust.

Thomson, P., \& Pennacchia, J. (2016). Disciplinary regimes of "care" and complementary alternative education. Critical Studies in Education, 57(1), 84-99. https://doi.org/10.1080/17508487.2016.1117506

Tipper, B. (2011). "A dog who I know quite well”: Everyday relationships between children and animals. Children's Geographies, 9(2), 145-165. https://doi.org/10.1080/14733285.2011.562378

Tooth, R., \& Renshaw, P. (2018). Children becoming emotionally attuned to "nature" through diverse place-responsive pedagogies. In A. Cutter-MacKenzie-Knowles, K. Malone, \& E. Barratt Hacking (Eds.), Research handbook on childhoodnature (Ch. 16). Springer International Handbooks of Education.

Tuck, E. (2011). Humiliating ironies and dangerous dignities: A dialectic of school pushout. International Journal of Qualitative Studies in Education, 24(7), 817-827. https://doi.org/10.1080/09518398.2011.632785

Tuck, E., \& Yang, K. W. (2011). Youth resistance revisited: New theories of youth negotiations of educational injustices. International Journal of Qualitative Studies in Education, 24(5), 521-530. https://doi.org/10.1080/09518398.2011.600274 
van Dooren, T. (2014). Care (Living Lexicon for the Environmental Humanities). Environmental Humanities, 5, 291-294. https:// environmentalhumanities.org/arch/vol5/5.18.pdf

Wood, N., \& Waite, L. (2011). Editorial: Scales of belonging. Emotion, Space, and Society, 4(4), 201-202. https://doi.org/10.1016/j. emospa.2011.06.005

Wright, S. (2015). More-than-human, emergent belongings: A weak theory approach. Progress in Human Geography, 39(4), $391-411$. https://doi.org/10.11770309132514537132

Yuval-Davis, N. (2006). Belonging and the politics of belonging. Patterns of Prejudice, 40(3), 197-214. https://doi. org/10.1080/00313220600769331 